\title{
A COMPREHENSIVE STUDY OF BLUNT ABDOMINAL TRAUMA AND ITS MANAGEMENT IN OUR CHENGALPATTU GOVERNMENT HOSPITAL
}

\author{
C. Srinivasan'1, J. Kirankumar², P. Pandian ${ }^{3}$, A. Arulselvan 4
}

${ }_{1}^{1}$ Professor, Department of General Surgery, Chengalpattu Government Medical College. ${ }^{2}$ Assistant Professor, Department of General Surgery, Chengalpattu Government Medical College. ${ }^{3}$ Assistant Professor, Department of General Surgery, Chengalpattu Government Medical College. ${ }^{4}$ Postgraduate Student, Department of General Surgery, Chengalpattu Government Medical College.

\section{ABSTRACT}

\section{BACKGROUND}

Injury has been man's constant companion since earliest times. Modern trauma care has been increasing in sophistication all the time. The abdomen is a Pandora's Box. It is commonly involved following blunt trauma. The trauma can be either from road traffic accidents, accidental fall from height, sports injury or violence. High velocity motor vehicle accidents account for $75-80 \%$ of blunt trauma of abdomen. Blunt trauma can result from either compression (secondary to a direct blow or against a fixed exter nal object) or from decelerating forces. The most commonly injured organs are the spleen, liver, small bowel, kidney, bladder, colon, rectum, diaphragm and pancreas. CT scanning has increased the identification of injuries. The care of the trauma patient is demanding and requires dedication, diligence and efficiency. Evaluating patients who have sustained blunt abdominal trauma remains one of the most challenging and resource-intensive aspects of acute trauma care. Missed intra-abdominal injuries and concealed haemorrhage are frequent causes of increased morbidity and mortality, especially in patients who survive the initial phase of an injury. Physical examination findings are sometimes unreliable for several reasons; including the presence of distracting injuries, associated chest injuries, an altered mental state and co-existing drug and alcohol intoxication in a patient. In view of increasing number of vehicles, consequent increase in high velocity road traffic accidents, rampant increase in construction work, this dissertation has been chosen to study blunt abdominal trauma, its different modalities of management and treatment outcomes.

Objectives-

- To evaluate the type and frequency of injury of various intra-abdominal organs in blunt trauma of the abdomen.

- To evaluate various modalities of treatment available with aim to reduce mortality and morbidity.

- To determine the management interventions carried out and treatment outcome at discharge.

\section{MATERIALS AND METHODS}

This Study has been undertaken in cases in Emergency Department from 1-5-2015 to 1-5-2016 presenting with blunt injury to abdomen of age group 15 to 75 years in Chengalpattu Govt. Medical College and Hospital.

\section{RESULTS}

The most likely person to have an abdominal trauma is a healthy middle aged adult male. Most of the injuries were due to road traffic accidents (27 cases). The next comes accidental falls (4) from height like from trees, roof tops, and accidental falls and bull gore injuries (3) and assault (1). Most common injury was hollow viscus perforation 22 cases, followed by splenectomy 6 cases, mesenteric tear 2 cases, liver injury 5 cases.

\section{CONCLUSION}

This study shows that number of deaths due to blunt abdominal trauma is more in young males than others. Major cause for this is RTA. Majority of victims show hollow viscus perforation followed by splenic injury.

\section{KEYWORDS}

Trauma, Blunt Injury, Splenic Injury, Bowel Injury, RTA, Management Methods.

HOW TO CITE THIS ARTICLE: Srinivasan C, Kirankumar J, Pandian P, et al. A comprehensive study of blunt abdominal trauma and its management in our Chengalpattu Government Hospital. J. Evolution Med. Dent. Sci. 2016;5(83):6223-6225, D0I: $10.14260 /$ Jemds/2016/1405

Financial or Other, Competing Interest: None.

Submission 03-06-2016, Peer Review 05-10-2016,

Acceptance 11-10-2016, Published 17-10-2016.

Corresponding Author:

Dr. C. Srinivasan

Professor of General Surgery,

Chengalpattu Medical College and Hospital

Chengalpattu.

E-mail: csrinivasan25@gmail.com

DOI: $10.14260 /$ jemds $/ 2016 / 1405$

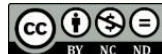

\section{BACKGROUND}

Since prehistoric times, the abdominopelvic cavity has been looked upon as one of the most vulnerable regions of the body and injuries involving it have always been considered very serious. As early as $460 \mathrm{BC}$, Hippocrates was aware of the danger to life caused by injury to liver and spleen. Blunt abdominal trauma is one of the leading preventable causes of the unnatural death in developed and developing countries. ${ }^{[1]}$ In civilian life, $75 \%$ of abdominal trauma is non-penetrating injuries. Blunt trauma is particularly deceptive as the clinical manifestations of the injury may be delayed for hours or days even though internal damage is serious and sometimes lethal. 
In open cases of abdominal trauma, the clinical manifestations, diagnosis and management will be easier but closed cases of abdominal trauma offer a great challenge to the treating surgeon.

\section{Causes of Blunt Abdominal Injuries}

Road traffic accidents, Fall from Heights, Warfare injuries, Battering, Sports accidents, Martial arts, Athletics, Mountaineering, etc. Two sets of factors, endogenous and exogenous, determine the types and degree of visceral damage sustained when blunt force traumatises the abdomen. ${ }^{[2]}$

\section{Endogenous Determinant in Blunt Abdominal Trauma}

Significant intrinsic factors, which help to determine the outcome of blunt abdominal injury reside in the viscera and their vasculature.

1. Solid organs (e.g. liver and spleen) are more readily lacerated by blows than hollow organs such as the (empty) stomach, intestines, and (empty) urinary bladder.[3]

2. Readily moveable or displaceable organs have considerable capacity to absorb the force of a blow, without serious injury, because of their ability to 'ride with the punch'. Thus, a blow to the abdomen or compression less readily damages normally attached ileum and jejunum than the fixed retroperitoneal duodenum.

3. The more distended a hollow viscus, the greater is its vulnerability to externally applied blunt force. A stomach filled with food and drink or a urinary bladder bulging with urine are more readily torn by a blow to the epigastrium or suprapubic region respectively than that when either is empty or only partially filled.[4]

\section{Exogenous Factors}

Exogenous factors which influence severity and nature of visceral lesions resulting from violence include:

1. Size and consistency of the traumatising object, e.g. fist, foot, etc.

2. Site of impact, e.g. epigastrium, hypochondrium, inferior rib cage, suprapubic area, costovertebral angle, flank, etc.

3. Speed and weight (force or energy) of the traumatising object.

4. Nature of the traumatising force, e.g., sharp impact or slow compression.

5. Strength of the abdominal wall.

6. Degree of abdominal "guarding" i.e., extent of protective contraction of abdominal musculature.

7. Pre-existing visceral status. The blunt force injuries of the abdominal organs are divided into i) Injuries of the parenchymatous viscera and ii) Injuries of the hollow abdominal viscera and their attachments.

\section{The Parenchymatous Viscera}

The most important organs in this group are the liver, spleen, kidneys, and pancreas. Generally since their consistency is firm, they are not easily ruptured by blunt force. They are also protected by bones like the ribs or are located deep in the abdomen, so that they are not easily reached except in severe injury cases. The principal complication, which causes death in injuries of the parenchymatous organ, is haemorrhage into the abdominal cavity.[5]

\section{The Hollow Abdominal Viscera}

The hollow abdominal viscera, including the gastrointestinal tract, the urinary bladder and the pregnant uterus, are injured by the same types of blunt forces as are the parenchymatous abdominal viscera, but the traumatic lesions which are produced and the complications which ensue are characteristic and dependent on their anatomic structure and exposed position in the abdomen. The stomach, duodenum and contracted urinary bladder are fairly well shielded by the skeleton or by their position in relation to other structures, but the intestine and the distended urinary bladder are protected only by the anterior abdominal wall and are therefore vulnerable to violence applied to the lower abdomen.[6] The stomach, duodenum and contracted urinary bladder are fairly well shielded by the skeleton or by their position in relation to other structures, but the intestine and the distended urinary bladder are protected only by the anterior abdominal wall and are therefore vulnerable to violence applied to the lower abdomen. ${ }^{[7]}$ The structure of the hollow viscera is much more fragile than that of the parenchymatous organ and serious injury may be inflicted on them by a comparatively slight degree of violence. ${ }^{8}$

\section{OBJECTIVES}

- To evaluate the type and frequency of injury of various intra-abdominal organs in blunt trauma of the abdomen.

- To evaluate various modalities of treatment available with aim to reduce mortality and morbidity.

- To determine the management interventions carried out and treatment outcome at discharge.

\section{MATERIALS AND METHODS}

Duration of Study- 1 year (May 2015 - May 2016).

Population to be Studied- Minimum of 35 cases.

Study Group- 15 to 75 yrs. age group.

Study Setting- Accident \& Emergency Ward, Department of General Surgery, Chengalpattu Medical College and Hospital, Chengalpattu.

\section{Inclusion Criteria}

- Patients presenting with history of recent assault by blunt and heavy object over abdomen.

- Road traffic accident with suspected blunt abdominal injury.

- History of fall from height.

- History of fall of heavy object over abdomen.

- Injuries occurring during natural calamities like earth quakes and landslides.

- Blunt trauma to abdomen in sports injury.

\section{Exclusion Criteria}

- Patients with penetrating/stab/gunshot injuries.

- Patients of paediatric age group.

Materials to be used

- Blood Analysis: Haemoglobin, Bleeding Time, Clotting Time.

- Serial haematocrit value.

- Urine Analysis.

- X-ray chest and abdomen.

- Four quadrant aspiration of abdomen.

- Diagnostic peritoneal lavage.

- Intravenous Contrast studies.

- Ultrasound abdomen.

- Computed Tomography(CT) scan. 


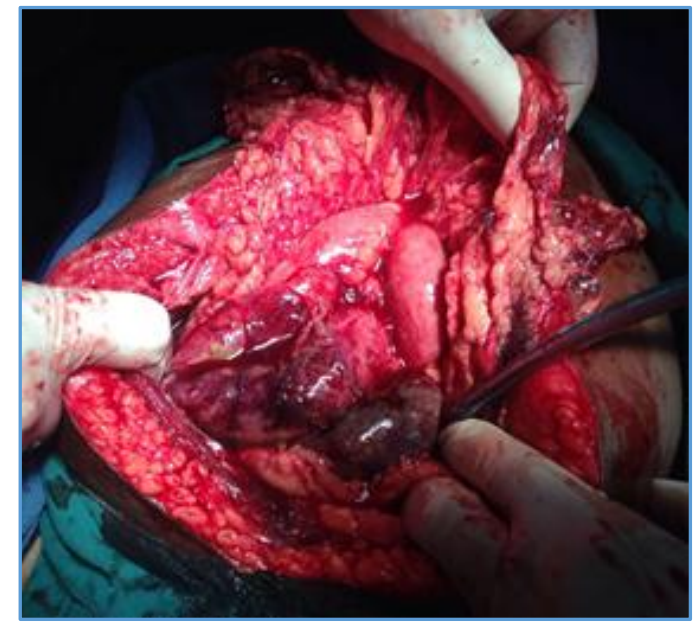

Fig. 1: Shows Mesenteric Injury causing Small bowel Gangrene following Road Traffic Accident

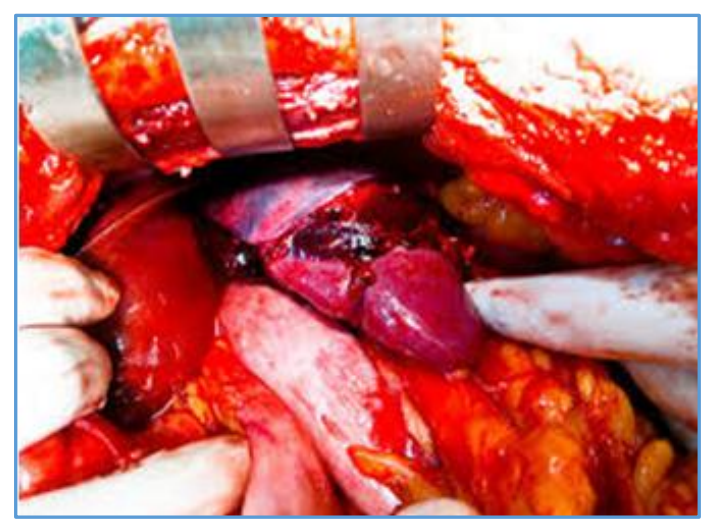

Fig. 2: Shows Grade III Splenic Injury Following Bull Gore Injury

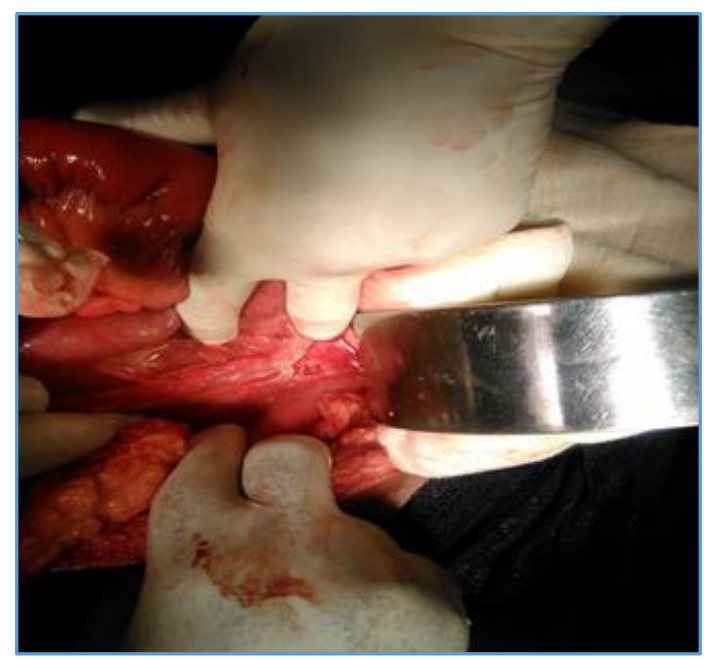

Fig. 3: Shows Transverse Perforation of Ileum

\section{RESULTS}

The most likely person to have an abdominal trauma is a healthy middle aged adult male. Most of the injuries were due to road traffic accidents (27 cases). The next comes accidental falls (4) from height like from trees, roof tops, and accidental falls and bull gore injuries (3) and assault 1. Most common injury was hollow viscus perforation 22 cases, followed by splenectomy 6 cases, mesenteric tear 2 cases, liver injury 5 cases.
Abdominal Viscera Involved

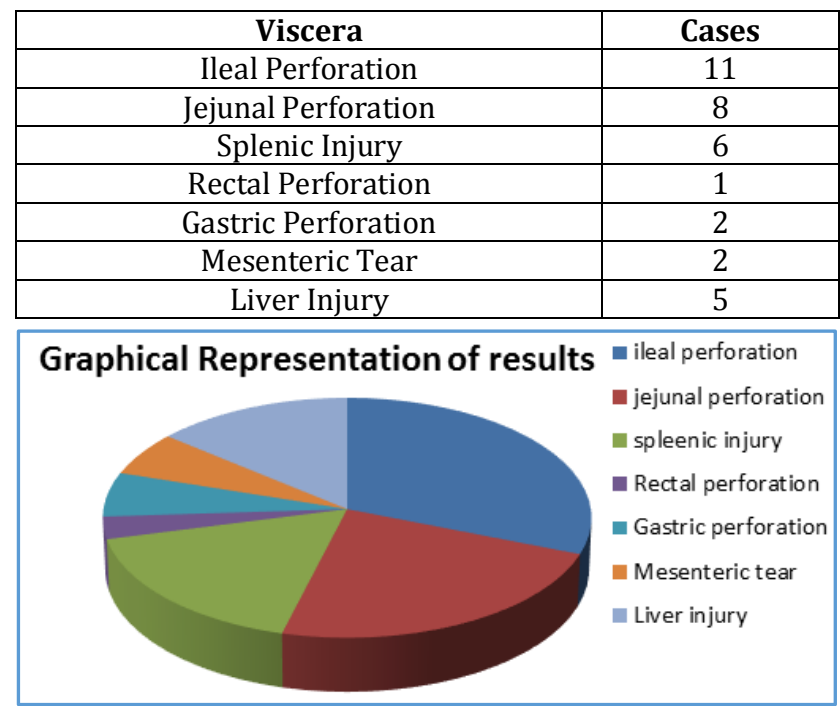

\section{DISCUSSION}

The study encompasses a data of pattern of blunt injuries to abdomen presenting in Chengalpattu Govt. Medical College during a period of 1 year which enlightens that majority of the injured are middle-aged males and most common injury sustained was hollow viscus perforation. Most cases were diagnosed early and managed systematically with nil intraoperative deaths and good postoperative outcome. Knowledge of patterns of blunt injury to abdomen helps the surgeon intraoperatively, and treating cases of blunt injury to abdomen improves the confidence of surgeon dealing with similar cases in future.

\section{CONCLUSION}

Blunt injury to abdomen is more serious and life endangering to patient, and more difficult and challenging to surgeons. Thorough knowledge on diagnosis and management of these cases improves the confidence levels of the surgeons, thus, cases can be managed much more effectively. Thorough understanding of patterns of injuries and early diagnosis, early resuscitation and timely surgical intervention helps the surgeon in managing these cases and save precious human life.

\section{REFERENCES}

1. Burke MP. Forensic medical investigation of motor vehicle incidents. $1^{\text {st }}$ edn. New York: Taylor and Francis 2007.

2. Saukko P, Knight B. Knight's Forensic Pathology. $3^{\text {rd }}$ edn. New York: Oxford University Press 2002.

3. Mathiharan K, Patnaik AK, eds. Modi's medical jurisprudence and toxicology. $23^{\text {rd }}$ edn. New Delhi: Lexis Nexis 2005.

4. Manson JK. The pathology of trauma. $3^{\text {rd }}$ edn. London: Arnold 2000.

5. Mant K. Blunt injury to the abdomen. In: Swaine A, ed. Taylor's principles and practice of medical jurisprudence wounds. $2^{\text {nd }}$ edn. Philadelphia: Henry C. Lea 2010.

6. Glaister J. Glaister's medical jurisprudence and toxicology. 10 $10^{\text {th }}$ edn. Williams and Wilkins 2006.

7. Reddy KSN. Essentials of forensic medicine and toxicology. $26^{\text {th }}$ edn. Hyderabad: Medical Book Company 2010.

8. Camps FE, Cameron JM, Lanham DJ. Wounds sequelae and complication. In: Practical forensic medicine. $2^{\text {nd }}$ edn. Hutchinson Medical 2010. 